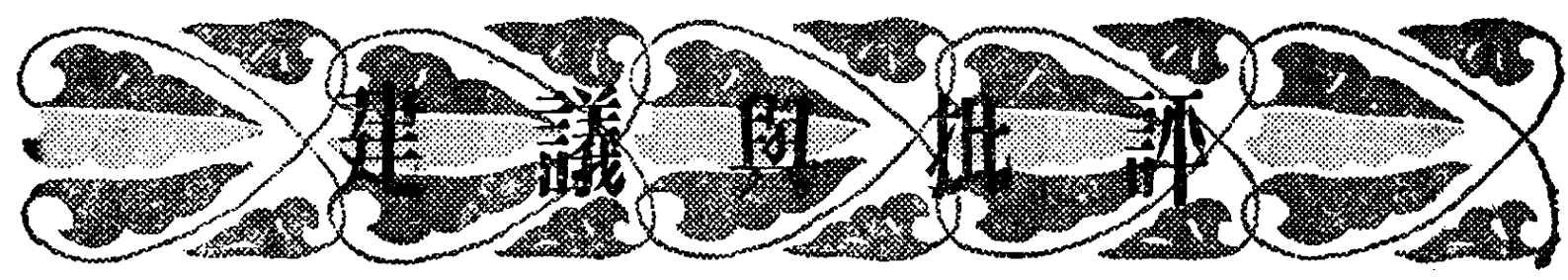

\section{在黄土丘陵區不宜大量 推廣梯田}

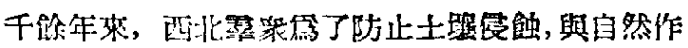

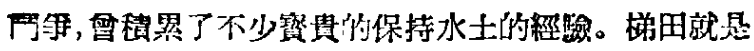

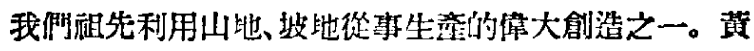

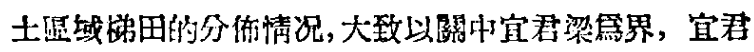

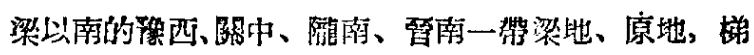
田比較普遍, 而陝北延安以北, 特別是緗德猄區, 坡上

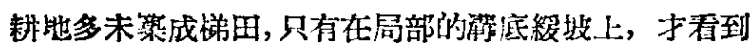

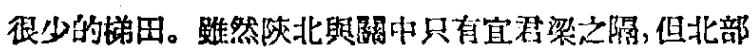

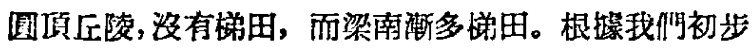
了解, 遏些情况可由下面事害來作解釋: 黃土的分佈規

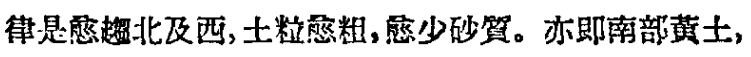

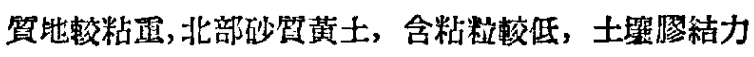

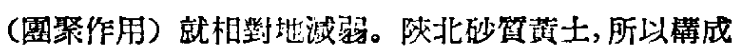

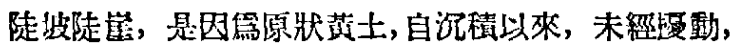

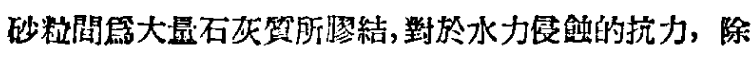

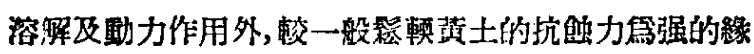

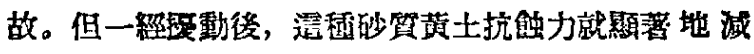

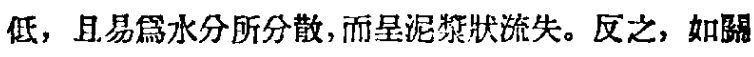

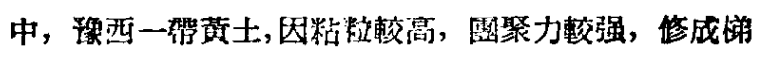

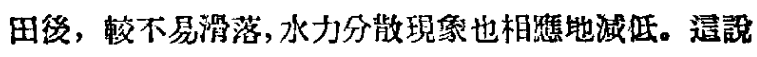

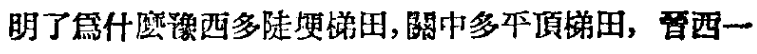

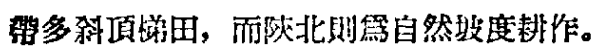

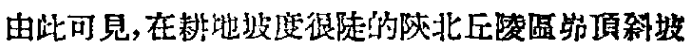
上烧乎没有涕田, 只有在路中一带原地、梁地上才見到

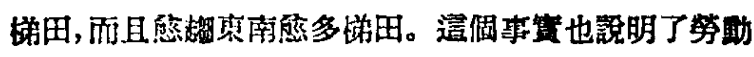

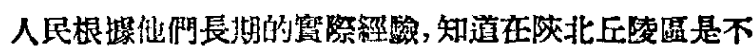
宜修築说田的。但有些同志一看到黄士 丘陵區没有梯

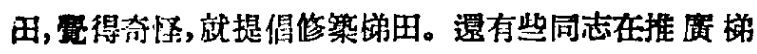

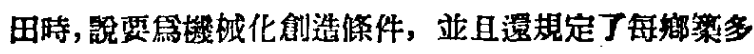

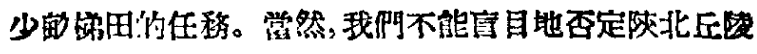
區不能修筑梯田, 但我們必须考空到営地的自然佟件, 是否適宜於修策梯田。

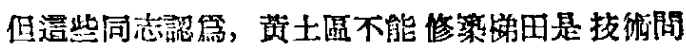
題 只工工程貿昷達到謤蕉，並逐年將埂培高即可。但

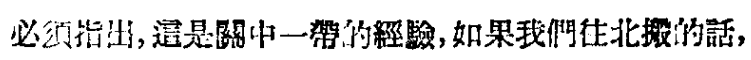

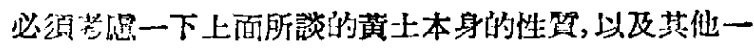

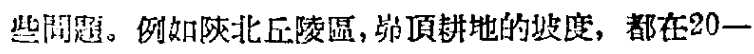

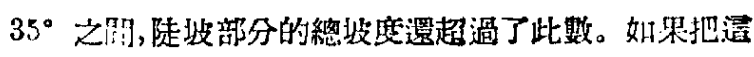

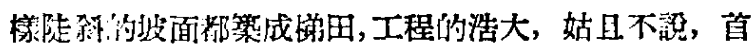

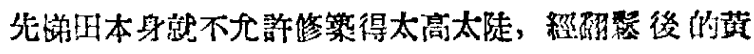

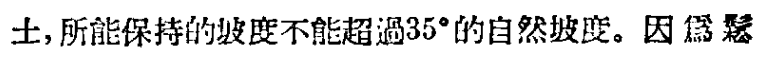
土超過了 $35^{\circ}$ ，土琵自然就滑落了。也有一部分 同志主

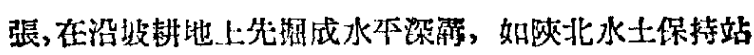
試睑地所作的那栐, 則幾来之內坡地上的泥沙就可沉入 哚解, 而不致流入河中。但這核修成的梯田中一牛以上

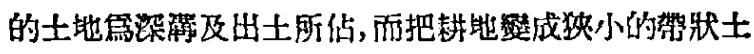

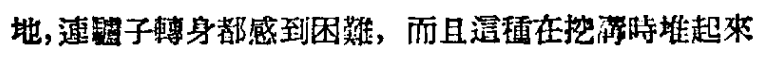
的黄士是站不住的,一程雨打水冲, 便逐㴬滑潟, 最後

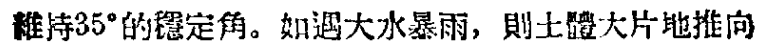
下诐(土滑作用)，因而造成了整個土繥的下滑。

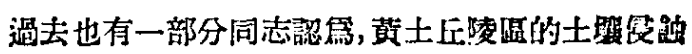

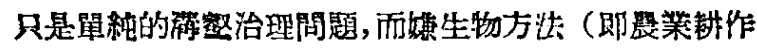

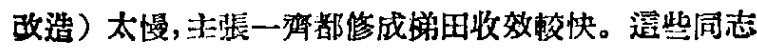

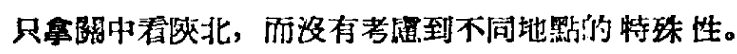
1953年曾有一部分地方幹部和罢篦反映说: “他們坐在 西安, 也不知道傸北的情况, 只淁我椚一部完成多少畧

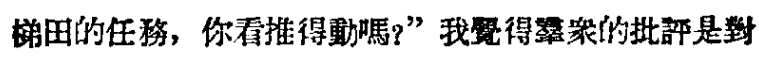
的, 不能拿西安比陆北, 也就與不能拿北京比西安一 傸北丘陵區的埸地上踓也存梯田，但是必須知道，

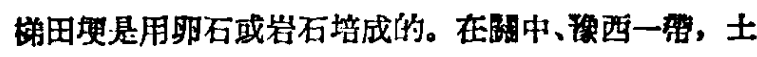

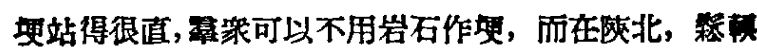
的黃土不能直立，且易崩场，只能以畉石修梯田，但在

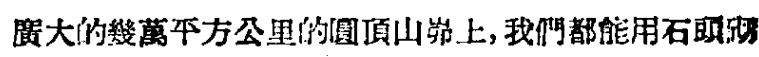
堁嗎? 㙷然是不可能的。

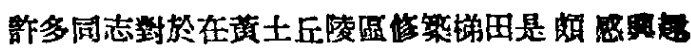

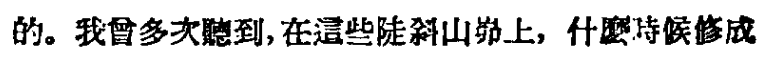

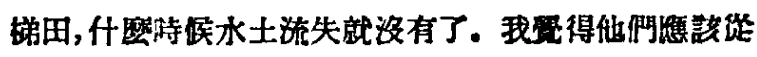


推筫通梯田而失敗的延安宸場來吸取数訓。我們不反

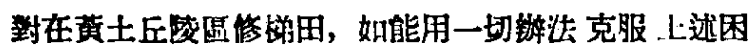

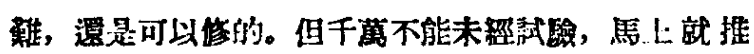

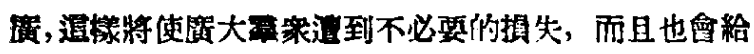

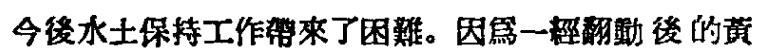
土坡，定蝕起來比原來的黄士更的品猛，甚至會到没有 可耕的表土的地步，並且把原來光滑的坡面分割成很多 的传蝕切解。

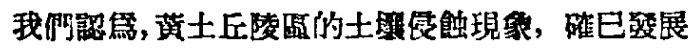

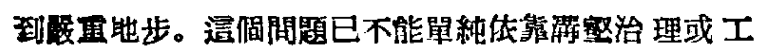

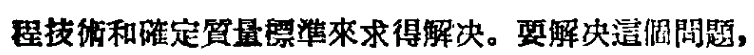
必页用全面的整套端法才可, 即由幽顶、耕種科披地、陡

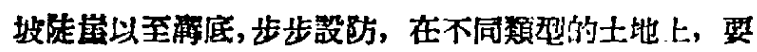

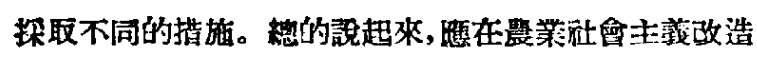
的前提下，用生物方法、明間工程方法以及其他工程方 法相結合的方法, 才可以收到水士保持的效果。任何一 種單一的田關工程挨施, 踓也有它的一定效果, 但也可 能志生一些副作用。造不是治本之法, 如果運用不掌, 逨治整也碳不上。

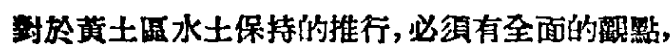

\section{對中國標準時區劃分的建䕙}

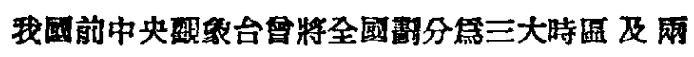

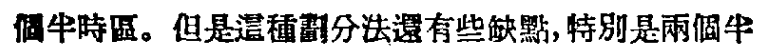
持區與國祭規定不相符合。

今天，我國社會主義建設正在大規模 進行, 交通 事菜日盆發眼，行政品霯也已櫂過調整，全國的摽淮時

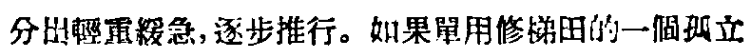

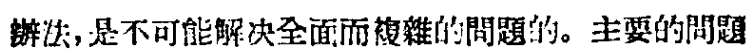

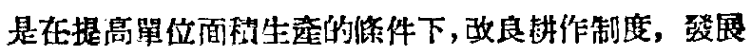

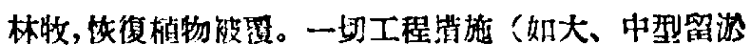
水厘、小型留淤土壩、田閂工程等) 雖然可以较快地造 行, 可以争取時閏, 但光靠工程㳻施遙是不能晖决根本

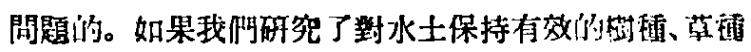

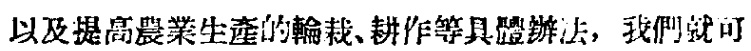

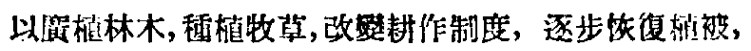

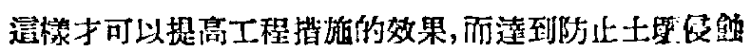

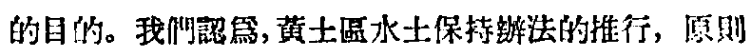

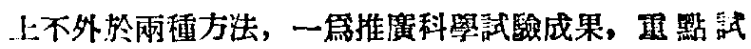

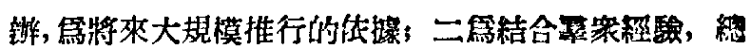

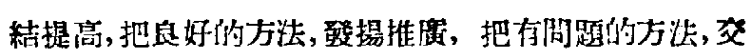
㢦驗單位就辫。在推行每一種水士保持方法時，必公考 菑到當地的自然條件，因地制宜，不可度日推行。梯田

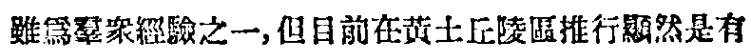
問題的。

\section{席承落}

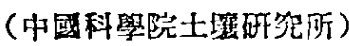

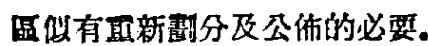

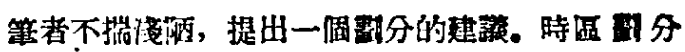
的原則, 我竘学有下面四點:

1. 我國東西所跨殌度很大，洔區不能分得過少。

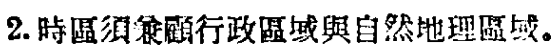

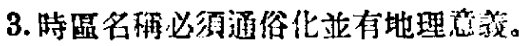

4. 缃與國際時區相衡接。

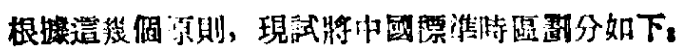

\begin{tabular}{|c|c|c|c|c|c|}
\hline 咱 & 新 藏 時 區 & 青 度 時 面 & 華西 時 㫜 & 東 南 洔 區 & 身北甠孟 \\
\hline 慗海子午絨 & (東艖) $75^{\circ}$ & $90^{\circ}$ & $105^{\bullet}$ & $120^{\circ}$ & $135^{\circ}$ \\
\hline 世界時孟 & 5 & 6 & 7 & 8 & 9 \\
\hline 括 & 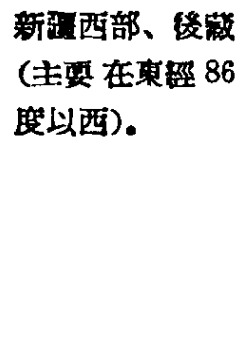 & 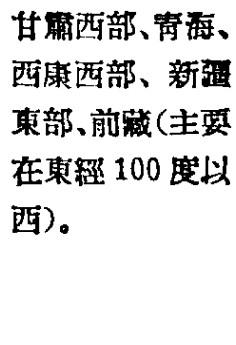 & 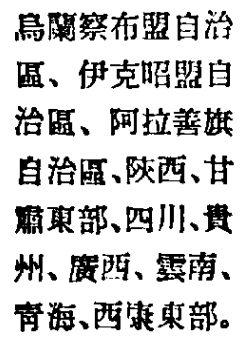 & 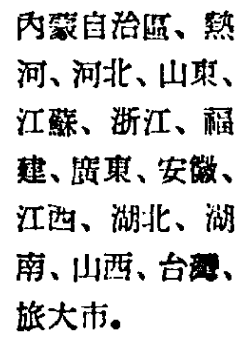 & $\begin{array}{l}\text { 黑能江、吉 } \\
\text { 林、䢰密(旅 } \\
\text { 大除外)。 }\end{array}$ \\
\hline 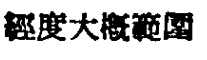 & $72-86^{\circ}$ & $86-100^{\circ}$ & $100-111^{\circ}$ & $111-122^{\circ}$ & $122-135^{\circ}$ \\
\hline 受時中心 & 伊密 & 哈窑、拉螣 & 閶州、昆明 & 北京、上海、算州 & 辰秦 \\
\hline
\end{tabular}

(下接 19 貣) 